\title{
Influence of Hydrodynamic Cavitation on Intensification of Laundry Aqueous Detergent Solution Preparation
}

\author{
Tadej Stepišnik Perdih* - Brane Širok - Matevž Dular \\ University of Ljubljana, Faculty of Mechanical Engineering, Slovenia
}

\begin{abstract}
Washing machines are one of the most energy and water demanding domestic appliances. Over years, a significant effort of the scientific community has been invested into making laundry more "sustainable". Nevertheless, the preparation of detergent solution has been entirely overlooked step of laundering. The preparation of aqueous detergent solutions in the currently available washing machines takes up to 10 minutes. In this work, we propose a design of a special rotary hydrodynamic cavitation generator, which would impact this process. New detergent dissolution rates have been experimentally tested on the laboratory model washing machine using the designed cavitation generator. The dissolution rates have been determined from the measurements of the undissolved detergent after the specific time of treatment. Additionally, the influence of hydrodynamic cavitation on that process has been isolated and investigated. To do so, two flow regimes have been established: the regime with cavitation present and the regime where cavitation was not present. In order to evaluate cavitational intensity, pressure oscillations inside cavitation generator have been recorded. Results indicate that cavitation significantly increases the detergent dissolution rates. In the cavitation flow regime, more than $80 \%$ of the detergent is dissolved in approximately 10 seconds. With no cavitation present, about 150 seconds are needed to dissolve the same amount of the detergent. Intensification of the process can be attributed to mechanical effects of cavitation. This research shows that use of the cavitation generators in the washing machines could lead to shorter washing programs and henceforth potential water and energy savings.
\end{abstract}

Keywords: hydrodynamic cavitation, rotary cavitation generator, cavitational intensity, washing machines, aqueous detergent solution

Highlights

- Hydrodynamic cavitation was used to prepare aqueous detergent solution.

- Special rotary hydrodynamic cavitation generator was designed.

- Cavitation significantly improves detergent dissolution rates.

- Cavitation generators could improve water and energy efficiency of washing machines.

\section{INTRODUCTION}

Washing machines are among most common devices worldwide and at the same time one of biggest consumers of household energy [1]. One can assume that already a minor improvement in a laundry process or a washing machine production will have a globally non-negligible effect.

Many advances in laundry technology and washing machines design are already reported in the literature. Teschler suggests the use of a variablespeed inverter electromotor [2]. Ivarsson et al. proposed sensors for fill and rinse control [3], which would reduce water and detergent consumption. Most of the energy in washing machine is used for water heating, therefore Persson investigated the use of hot-water circulation loop [4]. Drinking water consumption could be significantly reduced with use of recycled water [5] or rainwater [6] and lastly, improved detergent composition would make laundry less of an environmental threat, while maintaining washing performance [7].

Surprisingly, preparation of wash bath (aqueous detergent solution) is completely neglected by researchers. Our team aims to intensify the preparation of wash bath by utilizing cavitation and to our knowledge, this is the first research where cavitation is used for detergent solutions preparation.

The use of cavitation is drawing great attention of researchers from various fields. Cavitation is a physical phenomenon characterized by formation, growth and subsequent collapse of bubbles in a bulk liquid. The collapses of bubbles create local "hot spots", releasing extreme amounts of energy [8]. If the bubble collapse occurs symmetrically, pressure shock waves are created, which propagate microscopic turbulence - a phenomenon known as microstreaming [9]. Moreover, when cavitation bubble is in a proximity of a solid surface, asymmetric bubble implosion takes place, which results in a formation of microjets [10]. These violent circumstances are being widely utilised to clean solid surfaces in different industries and medical and scientific laboratories for over 40 years [11] and [12]. On the other hand, the use of cavitation in textile engineering gained scientific attention only in recent years. Nevertheless, cavitation shows great potential for textile finishing and textile washing purposes. Vouters et al. [13] report, that with the use 
of cavitation, water consumption can be reduced by $20 \%$ and energy consumption for $30 \%$ with a rise of the quality of products by the same textile finishing treatment. In work of Gogate [14] one can additionally find an in-depth overview of other applications of cavitation phenomena for process intensification and reactor designs.

Cavitation is also recognised as an efficient method to prepare solutions and emulsions for various purposes. Depending on the application, either chemical effects (such as temperature and pressure hot spots, free radical formation) or mechanical effects (such as high shear stress and turbulence, microjets and microstreaming) are harnessed [15]. Kentish et al. [16] used cavitation to prepare range of food grade emulsions, Sivakumar et al. [17] proposed cavitation as green technology for preparation of poorly watersoluble drugs in pharmacy and Hasanbeigi and Price [18] investigated how use of cavitation can optimise costs and reduce pollution in production of dyeing solutions in textile industry. Additionally, Patil and Pandit [19] showed that cavitation is energy efficient method to produce nano-suspensions and Sharma et al. [20] was investigating operating parameters of cavitation setup on the intensification of hydrogenation reactions.

This paper is focused on basic research that aims to improve the efficiency of commercial washing machines by utilizing cavitation. More precisely, we have investigated the use of cavitation for aqueous detergent solution preparation in washing machines. Washing machines currently available on the market prepare the washing dissolution in the drum. Water from the supply network enters the machine and is led through the detergent tray to carry the detergent into the drum. There the detergent is mixed with clothes and the dissolution starts due to the rotation of the drum. The dissolution process consists of two steps: i) the interaction between the solute and the solvent molecules at the solid-liquid interface and ii) the diffusion of the solute molecules away from the interface to the bulk [21]. Since the dissolution is sequential it can take up to 10 minutes or even more, to prepare an adequate aqueous detergent solution in a washing machine. We assume this process would be accelerated if the detergent would be washed into a special bath, where it would be exposed to cavitation before it enters the drum. This could be a major improvement of washing machines operation by shortening laundry duration and potentially saving energy. Our goal was to determine to what extent hydrodynamic cavitation contributes to the dissolution time.

\section{EXPERIMENTAL}

The experiments were conducted at the University of Ljubljana in the Laboratory for Water and Turbine Machines. For this purpose, special rotary hydrodynamic cavitation generator (RHCG) has been designed. The detergent dissolution rates were experimentally evaluated, for both cavitation and noncavitation flow regime, on a model washing machine. In addition, standardised tests with a magnetic stirrer were performed as a reference.

\subsection{Set-Up and Materials}

The experimental set-up (Fig. 1) was designed in a way to simulate an actual washing machine. Together with the rotary hydrodynamic cavitation generator, the experimental set-up consisted of a closed pressure tank, connection pipes and pressure (ABB 266 ast), flow (Bio-Tech: FCH-C-Ms-N) and temperature sensors (Fluke 51 II). Ports seen in Fig. 1 on the top of pressure vessel are used to fill the set-up with water and detergent. When operating, the mixture exits the vessel at the bottom, then it is led through RHCG, where it is exposed to cavitation. RHCG also serves as a pump. Water and detergent than flow through control valve and back to the pressure vessel. The RHCG was driven with a single-phase electromotor, which is already present in the most of the washing machines.

Two sets of experiments have been conducted one with cavitation present and one in non-cavitating flow regime (this was achieved by increasing the system pressure while the rotational frequency and

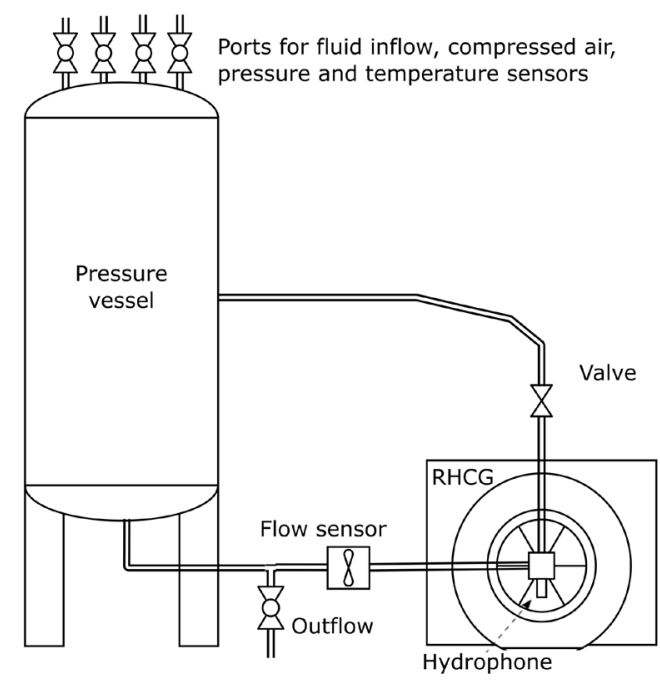

Fig. 1. Experimental set-up 
the flow rate were not altered). The dissolution rate experiments have been performed in alignment to the standard IEC 60456: Clothes washing machines for household use - Methods for measuring the performance. The tank was filled with 2 litres of water at $23.5^{\circ} \mathrm{C}$. 11 grams of standard IEC-A detergent purchased from WFK Institute, Germany, was added to water and left to be treated by the generator for a specified time. The RHCG rotational speed was set to $7000 \mathrm{rpm}$, which established a flow rate of $11.3 \mathrm{l} /$ min. In the cavitation regime, the tank was open to atmospheric pressure $(101 \mathrm{kPa})$. In an actual washing machine with implemented RHCG, this regime would correspond to the washing machine operation. The non-cavitating flow regime was achieved by closing the tank air valves and raising the static pressure (in the tank) to $253 \mathrm{kPa}$. Operating conditions are collected in Table 1. We used same method as Biluš et al. [22] for cavitation monitoring. A high-speed camera (Fastec HiSpec4 2G mono) was used in order to monitor cavitation presence. To evaluate cavitation intensity, pressure oscillations were recorded using hydrophone Reson TC4014. After treating the sample for the specified time (between 10 and 300 seconds from approximately 1 to 30 sample passages through the RHCG), the detergent solution was poured through the textile filter, so that the undissolved detergent remained on the filter. Filter textile $(100 \%$ cotton, swiss pique knit, yarn count 17 tex, double threaded) complied with the IEC 60456 standard requirements.

After the experiments, the filters were left to dry at ambient air for $24 \mathrm{~h}$. The filters were weighed on the precision scale (Tehtnica Exacta EB 3600), prior and after the experiment and the percentage of detergent residues were recorded.

We achieved the following uncertainties of the measured values: $\pm 1 \%$ for the flow rate, $\pm 0.5 \%$ for the system pressure and $\pm 0.8 \%$ for the medium temperature. Mass of the detergent was measured to $\pm 0.01 \mathrm{~g}$ and dynamic pressure oscillations to $\pm 2.6 \%$.

\subsection{Test Section - Rotary Hydrodynamic Cavitation Generator (RHCG)}

The design of the rotary hydrodynamic cavitation generator follows the basic principles of high shear mixing devices [23], adjusted so that it also generates cavitation. The RHCG is an assembly of rotor and stator discs (Fig. 2) with special geometry inside the closed chamber. Both the rotor and the stator diameters have diameter $50 \mathrm{~mm}$. They have 12 radial indentations, $3 \mathrm{~mm}$ deep $(u)$ and $4 \mathrm{~mm}$ wide. Unindented area of the rotor disc has been machined in a way that the surfaces are angled at $8^{\circ}(\alpha)$, giving them a sharp edge. The stator surface has not been modified. The distance between the rotor and the stator was set to $1 \mathrm{~mm}(\mathrm{~g})$. The whole assembly is illustrated in Fig. 3 and the details are given in Table 1 .
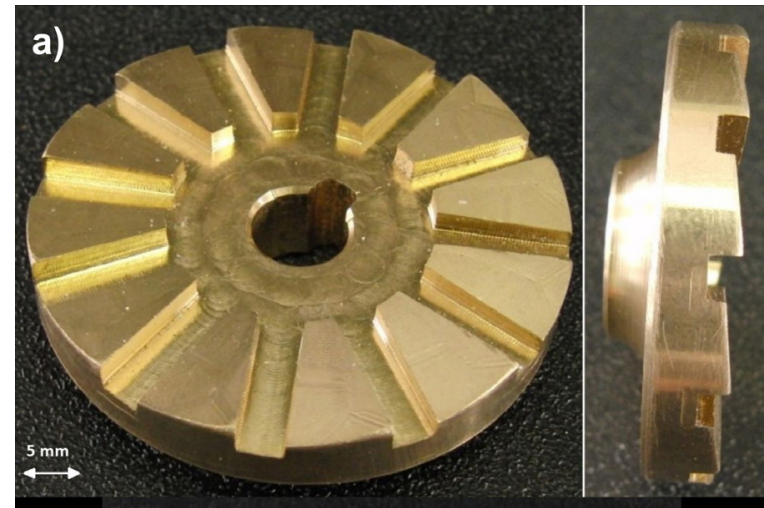

b)

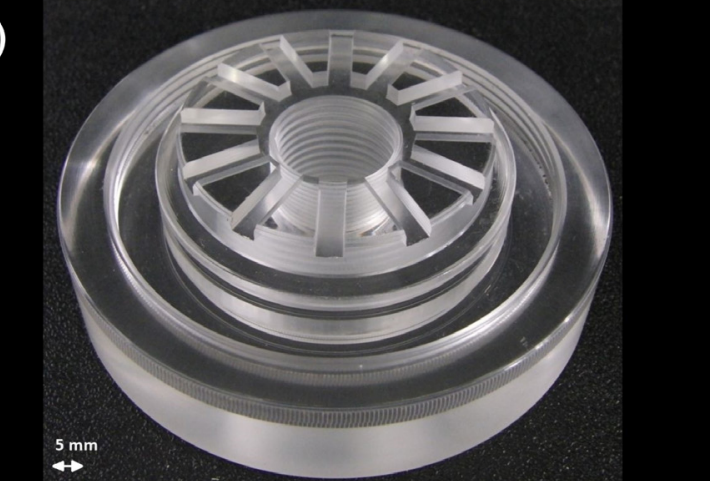

Fig. 2. a) Rotor and b) the stator of cavitation generator

Water and the detergent enter the RHCG in the axial direction through the stator. The RHCG operation causes periodically repeating pressure drops inside the chamber, due to relative movement of the two shear layers that form between the rotor and the stator. These conditions are favourable for hydrodynamic cavitation, hence before exiting in the radial direction, the mixture passes cavitation zones. Due to the rotation of the rotor, also centrifugal force is exerted on the fluid, which maintains the flow through the reactor. Because of that design, the cavitation generator can also replace a water recirculation pump in a washing machine.

Although acoustic cavitation is used in most of the aforementioned researches [13], [17], [18], [20], our device generates hydrodynamic cavitation. Its main advantages over acoustic cavitation are better potential for industrial and commercial scale applications, robust operation as well as improved energy efficiency [19] and [24] to [26]. In particular, the shear-induced 
cavitation generated with our device has proven to be even more effective than hydrodynamic cavitation generated on Venturi section, as it was showed by Zupanc et al. [27].
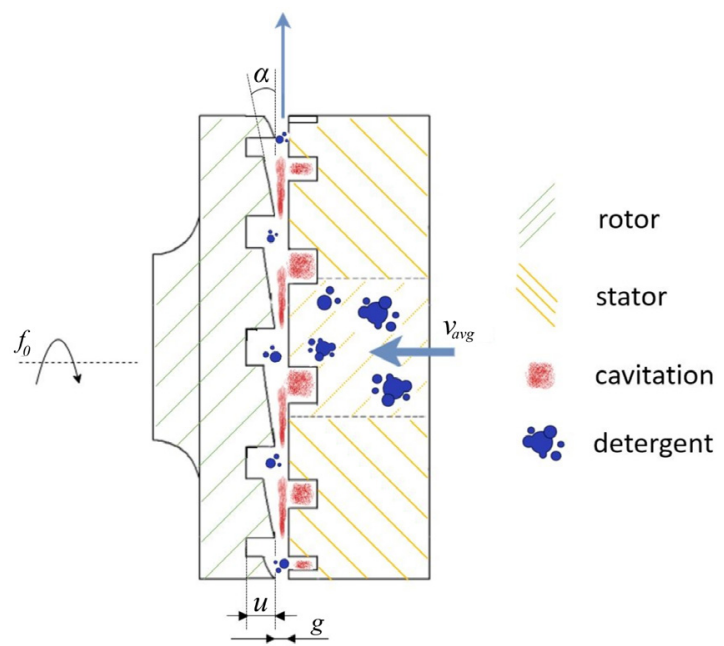

Fig. 3. Scheme of the cavitation generator assembly; water and detergent enter the RHCG in the axial direction through the stator; before exiting in the radial direction, the mixture passes cavitation zones

Table 1. Operating conditions and cavitation generator geometry details

\begin{tabular}{lcc}
\hline Operating parameters & Cavitating regime & Non-cavitating regime \\
\hline$p[\mathrm{kPa}]$ & 101 & 253 \\
\hline$g[\mathrm{~mm}]$ & 1 \\
\hline$u[\mathrm{~mm}]$ & 3 \\
\hline$\alpha\left[^{\circ}\right]$ & 8 \\
\hline$f_{0}\left[\min ^{-1}\right]$ & 7000 \\
\hline
\end{tabular}

\section{RESULTS}

24 experiments in the RHCG were performed in order to determine the detergent dissolution rate - at cavitating ( $p=1.01$ bar) and non-cavitating ( $p=2.53$ bar) flow regimes, both at the rotating frequency of $7000 \mathrm{rpm}\left(f_{0}\right)$. The lengths of exposure of the detergent to the RHCG were $10 \mathrm{~s}, 40 \mathrm{~s}, 70 \mathrm{~s}, 130 \mathrm{~s}$ and $300 \mathrm{~s}$ (this corresponds to approximately 1, 4, 7, 12 and 30 sample passages through the RHCG).

\subsection{Cavitation Monitoring}

Fig. 4 represents the sequences of images captured with the high-speed camera. In Fig. 4a, the RHCG front view is presented with indicated (the dashed rectangle) the high-speed camera observation window. Fig. $4 \mathrm{~b}$ shows images of the cavitating regime with

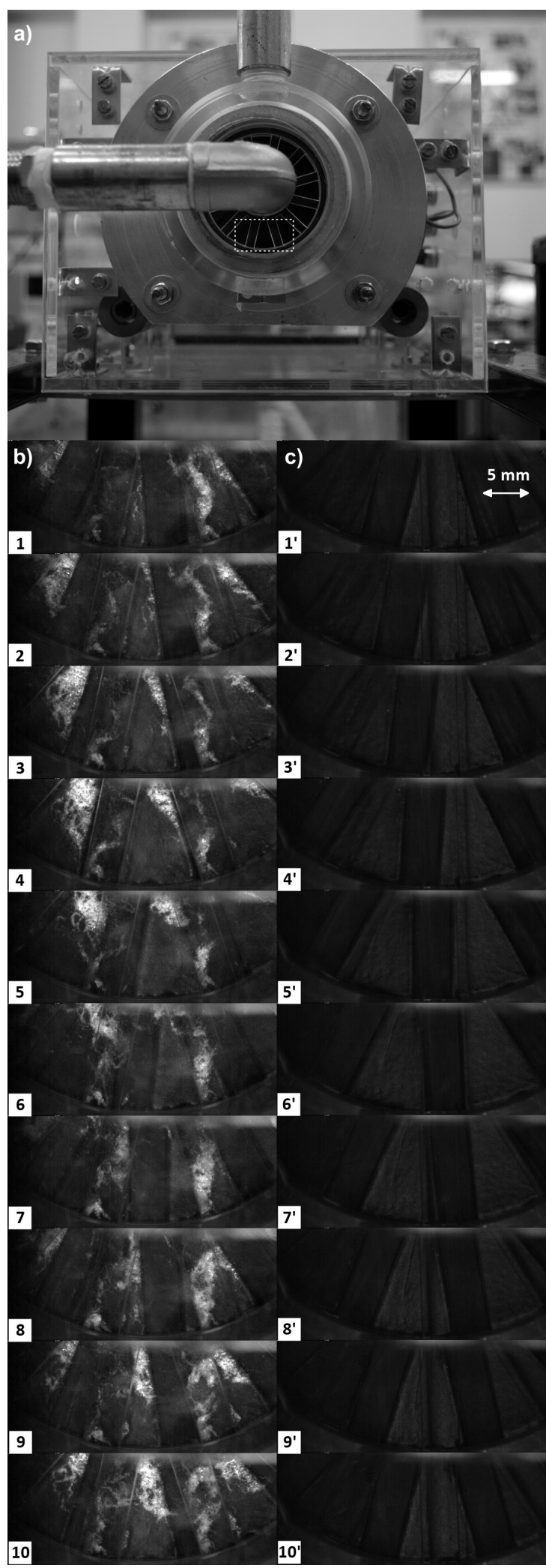

Fig. 4. a) Top image shows RHCG frontal view with marked camera observation window; b) cavitating regime and c) the non-cavitating operation of the RHCG 
the system pressure $101 \mathrm{kPa}$. Fig. 4c was recorded at elevated pressure $(253 \mathrm{kPa})$ and shows no presence of cavitation bubbles. The time difference between two frames is $0.1 \mathrm{~ms}$.

At atmospheric pressure, cavitation, which is seen as white clouds, can be clearly distinguished from the black painted rotor. We can notice, that cavitation is generated in two regions: the attached cavitation on the sharp edge of the rotor and the cavitation in stator indentations. This means that the most of the fluid flow is uniformly exposed to cavitation. When the system pressure is raised to $253 \mathrm{kPa}$ (Fig. 4b), no cavitation is present. The high-speed camera images confirm, that we have successfully established the two flow regimes (cavitating and non-cavitating one), by only changing the system pressure (the rotating frequency, the fluid temperature, the geometry and the flow rate were not altered) - this is important as we are not allowed to alter the rotating frequency of the rotor, to achieve comparable measurements.

The intensity of cavitation was evaluated by means of pressure oscillations. Bigger pressure amplitudes at bubble collapses represent higher cavitational intensity, [12], [15] and [22]. Fig. 5 shows pressure evolution recorded with the hydrophone, which was mounted exactly between the rotor and the stator. One can see that both amplitudes and gradients are higher for the cavitating regime in comparison to the non-cavitating regime. This means that detergent is exposed to much higher stresses when cavitation is generated in RHCG.

\subsection{Detergent Dissolution Rate}

The results are shown in Fig. 6. Triangles mark results obtained under the cavitating regime and diamonds to the tests under the non-cavitating regime. For comparison also dissolution rates using magnetic stirrer were performed (circles in Fig. 6): the tests complied with the IEC-A detergent solubility test acquired from IEC 60456 standard. Power trend lines are added for easier interpretation.

As expected, the dissolution rate is significantly improved when the RHCG is used in comparison to the magnetic stirrer. For the case when the solution is prepared with the magnetic stirrer, more than $35 \%$ of the detergent remains undissolved after 300 seconds of operation. In the same time, with using the RHCG in the non-cavitating regime, only about $15 \%$ of the detergent remains undissolved. The amount of the undissolved detergent after 300 seconds of the RHCG operation in cavitation regime is less than $5 \%$.

The improved dissolution rate when using the RHCG can be attributed to intensified mixing. Similar to other rotating reactors used for mixing purposes [23] and [28] the RHCG operation establishes high

a)

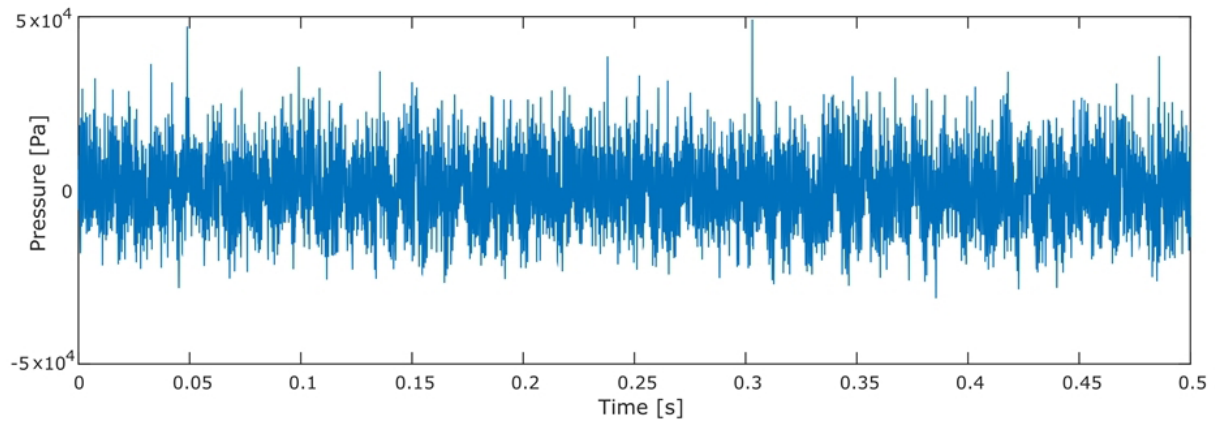

b)

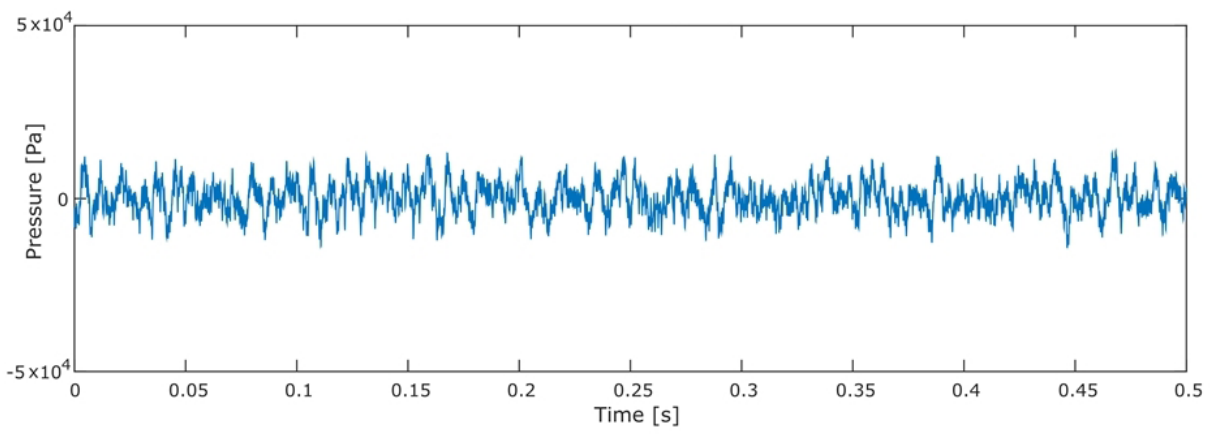

Fig. 5. Pressure evolution in case of the a) cavitating regime and b) the non-cavitating regime 


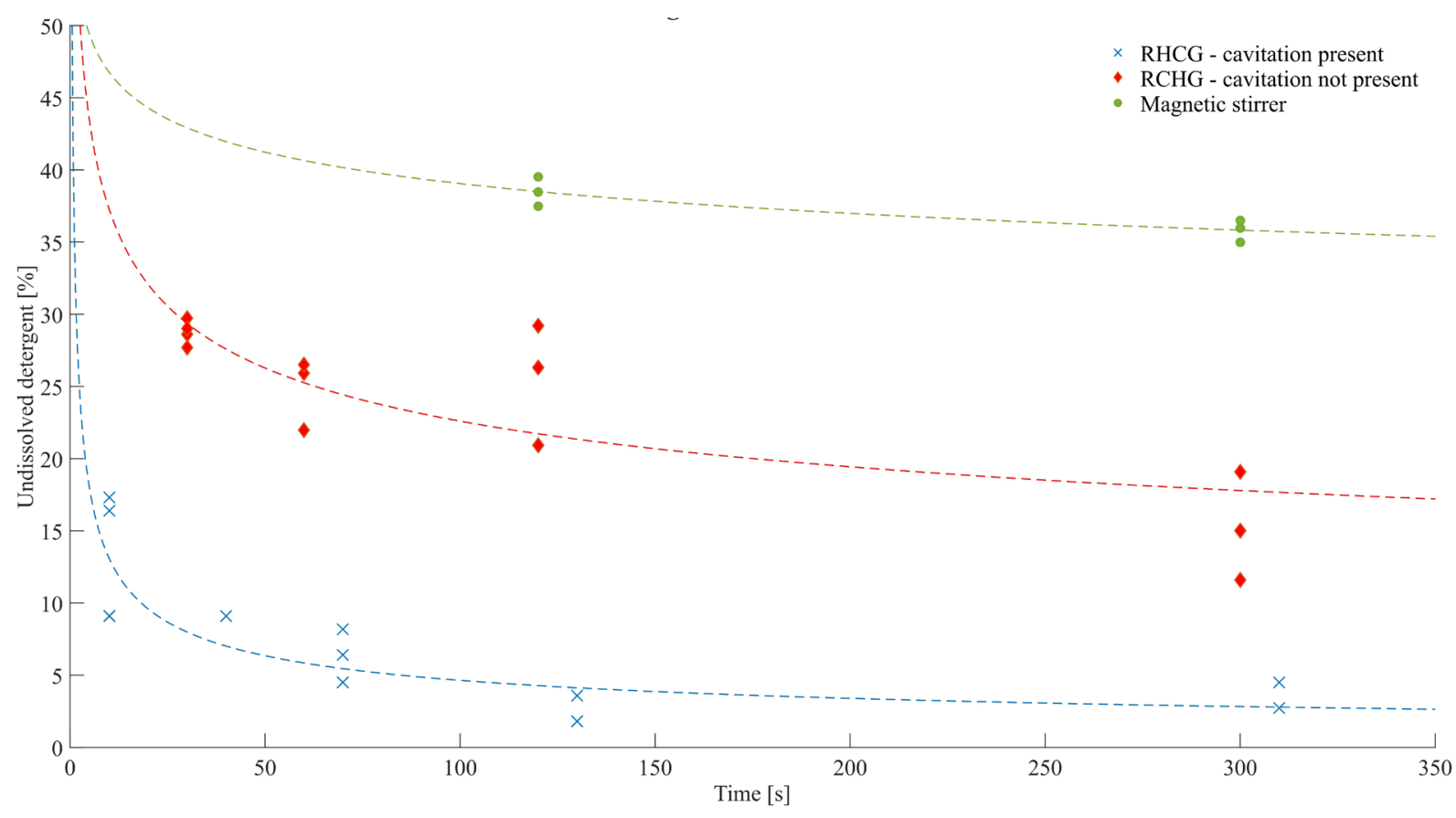

Fig. 6. The measurements of the detergent dissolution rate; significant difference in the amount of undissolved detergent is observed between operation in cavitating regime versus non-cavitating and furthermore the measurements with magnetic stirrer according to IEC 60456 standard

local turbulence levels inside the reactor chamber and enhances the solid-liquid mass transfer. This improves both steps of the dissolution process: the interactions between the solute (detergent) and the solvent (water) at the solid-liquid interface (first step), and especially the diffusion of the detergent to the bulk water (second step). Comparison of the results of the RHCG in cavitating and non-cavitating regimes furthermore indicates that cavitation has a substantial impact on the dissolution process. For objective assessment, ANOVA analysis of variance of the experiments was performed. The test confirms, that statistically significant difference with confidence level higher than $96 \%$ exists between the cavitating and the noncavitating regime $(\alpha<0.04)$.

Effect of cavitation on the dissolution process can be attributed to the violent collapses of cavitation bubbles. As evident from comparison of pressure evolution in Fig. 5, pressure pulsations in the cavitation regime increase for factor 2 in comparison to operation with no cavitation present. Henceforth high pressure pulsations and microjets due to cavitation [29] additionally increase the local turbulence and the detergent-water interaction and raising the dissolution rate. The difference in the amount of dissolved detergent is clearly demonstrated in Fig. 7. Images show two textile filters with detergent residues. The filter on the left belongs to the test where the detergent was exposed to the cavitation regime for 40 seconds, and the filter on the right corresponds to the test after the exposure to the non-cavitating regime for the same period of time ( 40 seconds).

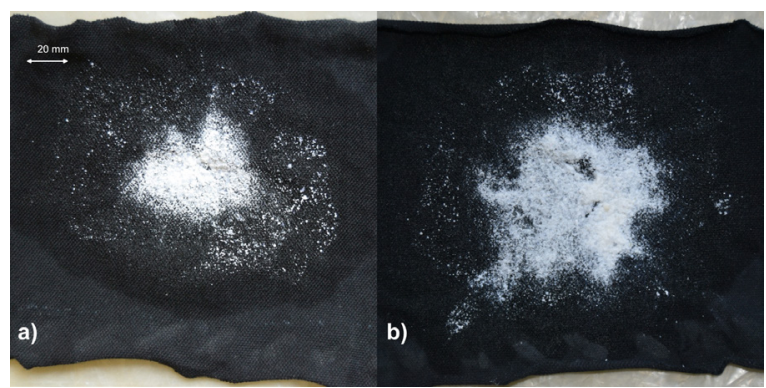

Fig. 7. The detergent residues on the textile filters for: a) the cavitation regime with $1.0 \mathrm{~g}$ of the detergent remained on the filter and $\mathrm{b}$ ) the non-cavitation regime with $3.2 \mathrm{~g}$ of the detergent remained on the filter

The difference in dissolution rates is especially evident in the initial stages of experiments. With the cavitation regime, approximately $80 \%$ of the detergent is dissolved within the first few seconds of the RHCG operation. When the RHCG operates at the same rotation frequency but without cavitation, 150 seconds are required to dissolve the same amount of 
the detergent. The dissolution rates decrease with the passing time for both flow regimes. The trend can be described by a power law. A similar trend can also be recognised for dispersion kinetics of other dispersing machines such as a dissolver, a high-pressure homogenizer or a stirred media mill [30]. This is because the probability of successful solute-solvent interactions in the reactor is gradually decreasing.

\section{CONCLUSIONS AND DISCUSSION}

Our work indicates, that the rotary hydrodynamic cavitation generator substantially improves the preparation of the detergent washing dissolution and thus the washing machine performance. Implementation of such a device would shorten the washing program in general. In addition, the RHCG could tackle other identified issues related to detergent solution, such as: i) improved mixture homogeneity, which would result in improved washing effect and in decrease water consumption, ii) improved detergent solution rinsing, due to break up of detergent agglomerates - Sauter et al. [31] used cavitation for de-agglomeration of nanoparticles and Parivnzadeh et al. [32] studied cavitation assisted cotton processing with softener. They argued, that the reason for enhanced treatment is cavitation de-agglomeration of softener. We predict that cavitation has a similar effect to detergent agglomerates and therefore a lower volume of water is required to rinse smaller detergent particles.

Furthermore we assume that the implementation of the RHCG would have negligible if not beneficial effect on the energy consumption of the washing machines because: i) cavitation would assist the dissolution process and reduce the operating time for roughly 10 minutes, ii) the RHCG also operates as a pump and would replace the existing water circulation pump and iii) most of the energy required to generate cavitation is eventually transformed into heat, which, in case of washing machine, could be balanced by the reduction of the power consumption of electric water heaters.

In addition to the detergent solution preparation, the RHCG or similar cavitation generators, could enhance other aspects of a washing machine operation. One example is a washing performance. Several research groups worldwide are studying ultrasonic textile cleaning. Leading mechanism of ultrasonic cleaning is in fact acoustically generated cavitation. Gallego-Juarez et al. [33] developed semiindustrial system for textile washing in liquid layers, where Gotoh et al. [34] and Uzun and Patel [35] used ultrasonic cavitation bath. They achieved comparable or better washing results than the horizontal-axis washing machine, causing less damage to the textile.

Another important subject related to current development trends of laundering is microbial deactivation. High washing temperatures and aggressive detergents from the past are nowadays replaced by milder conditions: low temperatures and biodegradable detergents. Studies show, that various bacteria and fungi species are capable of surviving inside washing machines [36] and [37] under such circumstances. This could present a health risk [36], or development of malodour [37]. Researchers will be forced to find solutions for those problems. One more time harnessing cavitation may bring desired results. Use of cavitation for pathogen deactivation [38] and [39] and wastewater treatment is well developed [26] and [27].

Lastly, cavitation may have a potential to mitigate limescale. Limescale can cause serious issues to washing machine heat exchangers. Already a thin layer of scale reduces a heat exchanger efficiency and can lead to component failure. Review paper of Heath et al. [40] shows that cavitation/scale interaction is complex, but a lot of effort is invested in its research.

In previous paragraphs, we pointed out what aspects of washing machines may be improved with cavitation in addition to wash bath preparation. Extensive research is still needed in order to determine if also RHCG, or any other small scale cavitation generator, can achieve such results. However, use of cavitation may be the answer for sustainable and effective laundry.

\section{ACKNOWLEDGEMENTS}

The authors gratefully acknowledge the support by Slovenian Research Agency.

\section{REFERENCES}

[1] Bansal, P., Vineyard, E., Abdelaziz, O. (2011). Advances in household appliances - a review. Applied Thermal Engineering, vol. 31, no. 17-18, p. 3748-3760, D0l:10.1016/j. applthermaleng.2011.07.023.

[2] Teschler, L. (2008). Motors move toward more efficiency, Machine Design, vol. 7, p. 74-78.

[3] Ivarsson, P., Johansson, M., Höjer, N.E., Krantz-Rülcker, C., Winquist, F., Lundström, I. (2005). Supervision of rinses in a washing machine by a voltammetric electronic tongue. Sensors and Actuators B: Chemical, vol. 108, no. 1-2, p. 851 857, DOl:10.1016/j.snb.2004.12.088.

[4] Persson, T. (2007). Dishwasher and washing machine heated by a hot water circulation loop. Applied Thermal 
Engineering, vol. 27, no. 1, p. 120-128, D0l:10.1016/j. applthermaleng.2006.05.005.

[5] Chen, Z., Ngo, H.H., Guo, W.S., Listowski, A., O'Halloran, K., Thompson, M., Muthukaruppan, M. (2012). Multi-criteria analysis towards the new end use of recycled water for household laundry: A case study in Sydney. Science of the Total Environment, vol. 438, p. 59-65, D0I:10.1016/j. scitotenv.2012.08.019.

[6] Morales-Pinzón, T., Lurue-a, R., Gabarrell, X., Gasol, C.M., Rieradevall, J. (2014). Financial and environmental modelling of water hardness - Implications for utilising harvested rainwater in washing machines. Science of the Total Environment, vol. 470-471, p. 1257-1271, D0l:10.1016/j. scitotenv.2013.10.101.

[7] Vojcic, L., Pitzler, C., Körfer, G., Jakob, F., Ronny, M., Maurer, K.H., Schwaneberg, U. (2015). Advances in protease engineering for laundry detergents. New Biotechnology, vol. 32, no, 6, p. 629-6346, D0I:10.1016/j.nbt.2014.12.010.

[8] Suslick, K.S., Eddingaas, N.C., Flannigan, D.J., Hopkins, S.D., Xu, H. (2011). Extreme conditions during multibubble cavitation: Sonoluminescence as a spectroscopic probe. Ultrasonics Sonochemistry, vol. 18, no. 4, p. 842-846, D0I:10.1016/j.ultsonch.2010.12.012.

[9] Davidson, B.J., Riley, N. (1971). Cavitation microstreaming. Journal of Sound and Vibration, vol. 15, p. 217-233, DOI:10.1016/0022-460X(71)90536-0.

[10] Gogate, P.R., Pandit, A.B. (2000). Engineering design methods for cavitation reactors II: Hydrodynamic cavitation. AIChE Journal, vol. 46, no. 8, p. 1641-1649, D0l:10.1002/ aic. 690460815 .

[11] Mason, T.J. (2016). Ultrasonic cleaning: An historical perspective. Ultrasonics Sonochemistry, vol. 29, p. 519-523, D0I:10.1016/j.ultsonch.2015.05.004.

[12] Verhaagen, B., Fernández Rivas, D. (2016). Measuring cavitation and its cleaning effect. Ultrasonics Sonochemistry, vol. 29, p. 619-628, D0l:10.1016/j.ultsonch.2015.03.009.

[13] Vouters, M., Rumeau, P., Tierce, P., Costes, S. (2004). Ultrasounds: an industrial solution to optimise costs, environmental requests and quality for textile finishing. Ultrasonics Sonochemistry, vol. 11, no. 1, p. 33-38, DOI:10.1016/S1350-4177(03)00113-5.

[14] Gogate, P.R. (2008). Cavitational reactors for process intensification of chemical processing applications: A critical review. Chemical Engineering and Processing: Process Intensification, vol. 47, no. 4, p. 515-527, D0l:10.1016/j. cep.2007.09.014.

[15] Gogate, P.R., Sutkar, V.S., Pandit, A.B. (2011). Sonochemical reactors: Important design and scale up considerations with a special emphasis on heterogeneous systems. Chemical Engineering Journal, vol. 166, no. 3, p. 1066-1082, Dol:10.1016/j.cej.2010.11.069.

[16] Kentish, S., Wooster, T.J., Ashokkumar, M., Balachandran, S., Mawson, R., Simons, L. (2008). The use of ultrasonics for nanoemulsion preparation. Innovative Food Science and Emerging Technologies, vol. 9, no. 2, p. 170-175, DOI:10.1016/j.ifset.2007.07.005.

[17] Sivakumar, M., Tang, S.Y., Tan, K.W. (2014). Cavitation technology - a greener processing technique for the generation of pharmaceutical nanoemulsions. Ultrasonics Sonochemistry, vol. 21, no. 6, p. 2069-2083, D0l:10.1016/j. ultsonch.2014.03.025.

[18] Hasanbeigi, A., Price, L. (2015). A technical review of emerging technologies for energy and water efficiency and pollution reduction in the textile industry. Journal of Cleaner Production, vol. 95, p. 30-44, D0l:10.1016/j.jclepro.2015.02.079.

[19] Patil, M.N., Pandit, A.B. (2007). Cavitation - A novel technique for making stable nano-suspensions. Ultrasonics Sonochemistry, vol. 14, no. 15, p. 519-530, D0l:10.1016/j. ultsonch.2006.10.007.

[20] Sharma, A., Bapat, P.S., Gogate, P.R., Gastgar, S.N., Pandit, A.B. (2009). Process intensification of hydrogenation reactions using cavitation: Modelling the effect of solvent and catalyst. Chemical Engineering and Processing: Process Intensification, vol. 48, no. 1, p. 432-437, D0l:10.1016/j.cep.2008.05.008.

[21] Allaboun, H., Alkhamis, K.A., Al Jbour, N.D. (2007). Effect of surfactant on dissolution of spherical particles in micellar systems. European Journal of Pharmaceutics and Biopharmaceutics, vol. 65, no. 2, p. 188-197, D0l:10.1016/j. ejpb.2006.07.017.

[22] Biluš, I., Bombek, G., Hočevar, M., Širok, B., Cencič, T., Petkovšek, M. (2014). The experimental analysis of cavitationg structure fluctuations and pressure pulsations in the cavitation station. Strojniški vestnik - Journal of Mechanical Engineering, vol. 60, no. 3, p. 147-157, D0I:10.5545/sv-jme.2013.1462.

[23] Zhang, J., Xu, S., Li, W. (2012). High shear mixers: A review of typical applications and studies on power draw, flow pattern, energy dissipation and transfer properties. Chemical Engineering and Processing: Process Intensification, vol. 5758, p. 25-41, D0I:10.1016/j.cep.2012.04.004.

[24] Arrojo, S., Benito, Y. (2008). A theoretical study of hydrodynamic cavitation. Ultrasonics Sonochemistry, vol. 15, no. 3, p. 203-211, D0I:10.1016/j.ultsonch.2007.03.007.

[25] Bagal, M.V., Gogate, P.R. (2014). Wastewater treatment using hybrid treatment schemes based on cavitation and Fenton chemistry: A review. Ultrasonics Sonochemistry, vol. 21, no. 1, p. 1-14, DOI:10.1016/j.ultsonch.2013.07.009.

[26] Sivakumar, M., Pandit, A.B. (2002). Wastewater treatment: A novel energy efficient hydrodynamic cavitational technique. Ultrasonics Sonochemistry, vol. 9, no. 3, p. 123-131, DOI:10.1016/S1350-4177(01)00122-5.

[27] Zupanc, M., Kosjek, T., Petkovšek, M., Dular, M., Kompare, B., Širok, B., Stražar, M., Heath, E. (2014). Shear-induced hydrodynamic cavitation as a tool for pharmaceutical micropollutants removal from urban wastewater. Ultrasonics Sonochemistry, vol. 21, no. 3, p. 1213-1221, D0l:10.1016/j. ultsonch.2013.10.025.

[28] Visscher, F., van der Schaaf, J., Nijhuis, T.A., Schouten, J.C. (2013). Rotating reactors - A review. Chemical Engineering Research and Design, vol. 91, no. 10, p. 1923-1940, D0I:10.1016/j.cherd.2013.07.021.

[29] Dular, M., Bachert, B., Stoffel, B., Širok, B. (2004). Relationship between cavitation structures and cavitation damage. Wear, vol. 257, no. 11, p. 1176-1184, D0l:10.1016/j. wear.2004.08.004.

[30] Schilde, C., Kampen, I., Kwade, A. (2010). Dispersion kinetics of nano-sized particles for different dispersing machines. 
Chemical Engineering Science, vol. 65, no. 11, p. 3518-3527, D0I:10.1016/j.ces.2010.02.043.

[31] Sauter, C., Emin, M.A., Schuchmann, H.P., Tavman, S. (2008). Influence of hydrostatic pressure and sound amplitude on the ultrasound induced dispersion and de-agglomeration of nanoparticles. Ultrasonics Sonochemistry, vol. 15, no. 4, p. 517-523, D0I:10.1016/j.ultsonch.2007.08.010.

[32] Parvinzadeh, M., Memari, N., Shaver, M., Katozian, B., Ahmadi, S., Ziadi, I. (2010). Influence of ultrasonic waves on the processing of cotton with cationic softener. Journal of Surfactants and Detergents, vol. 13, no. 2, p. 135-141, D0I:10.1007/s11743-009-1158-y.

[33] Gallego-Juarez, J.A., Riera, E., Acosta, V., Rodríguez, G., Blanco, A. (2010). Ultrasonic system for continuous washing of textiles in liquid layers. Ultrasonics Sonochemistry, vol. 17, no. 1, p. 234-238, D0I:10.1016/j.ultsonch.2009.06.005.

[34] Gotoh, K., Harayama, K., Handa, K. (2015). Combination effect of ultrasound and shake as a mechanical action for textile cleaning. Ultrasonics Sonochemistry, vol. 22, p. 412421, D0I:10.1016/j.ultsonch.2014.05.005.

[35] Uzun, M., Patel, I. (2010). Mechanical properties of ultrasonic washed organic and traditional cotton yarns. Journal of Achievements in Materials and Manufacturing Engineering, vol. 43, no. 2, p. 608-612.
[36] Novak Babič, M., Zalar, P., Ženko, B., Schroers, H.J., Džeroski, S., Gunde-Cimerman, N. (2015). Candida and Fusarium species known as opportunistic human pathogens from customer-accessible parts of residential washing machines. Fungal Biology, vol. 119, no. 2-3, p. 95-113, D0l:10.1016/j. funbio.2014.10.007.

[37] Munk, S., Johansen, C., Stahnke, L.H., Adler-Nissen, J. (2001). Microbial survival and odor in laundry. Journal of Surfactants and Detergents, vol. 4, no. 4, p. 385-394, D0l:10.1007/ s11743-001-0192-2.

[38] Yusof, N.S.M., Babgi, B., Alghamdi, Y., Aksu, M., Madhavan, J., Ashokkumar, M. (2016). Physical and chemical effects of acoustic cavitation in selected ultrasonic cleaning applications. Ultrasonics Sonochemistry, vol. 29, p. 568-576, DOI:10.1016/j.ultsonch.2015.06.013.

[39] Šarc, A., Oder, M., Dular, M. (2014). Can rapid pressure decrease induced by supercavitation efficiently eradicate Legionella pneumophilabacteria?. Desalination and Water Treatment, vol. 57, no. 5, p. 2184-2194, Dol:10.1080/1944 3994.2014.979240.

[40] Heath, D., Širok, B., Hočevar, M., Širok, B., Pečnik, B. (2013). The use of the cavitation effect in the mitigation of CaCO3 deposits. Strojniški vestnik - Journal of Mechanical Engineering, vol. 59, no. 4, p. 203-215, D0l:10.5545/svjme.2012.732. 